\title{
Diapause in Drosophila melanogaster females: a genetic analysis
}

\author{
KAREN D. WILLIAMS \& MARLA B. SOKOLOWSKI* \\ York University, Department of Biology, Toronto, Ontario, Canada, M3J 1P3
}

\begin{abstract}
Female Drosophila melanogaster exhibit ovarian diapause at low temperatures and short day lengths. We found that $D$. melanogaster isofemale lines from Windsor (Ontario, Canada) had a significantly higher percentage of females in diapause than did those from Cartersville (Georgia, U.S.A.). To investigate the heredity of this trait, we performed a 16-reciprocal cross analysis using two extreme isofemale lines called $\mathrm{W}$ and $\mathrm{C}$. We found that diapause in D. melanogaster is inherited as a simple autosomal recessive trait with the $\mathrm{C}$ response (less flies in diapause) completely dominant to the $\mathrm{W}$ one. Maternal and cytoplasmic factors did not affect differences in diapause in these lines. The result of our genetic analysis of diapause in D. melanogaster opens many avenues for the genetic dissection of this ecologically relevant trait.
\end{abstract}

Keywords: Drosophila melanogaster, genetic analysis, ovarian diapause.

\section{Introduction}

Adaptations to seasonal variability, such as diapause, allow organisms to persist throughout the stress of adverse conditions. These adaptations allow the organism to 'escape in time' (Dingle, 1978) by delaying their growth or reproduction and thus increasing their chances of survival. Many organisms rely on cues such as changes in photoperiod to measure time and initiate this escape response. Variation in these responses may be affected by both genetic and environmental factors (Dingle, 1978; Danks, 1987). In the present paper we study the hereditary basis of ovarian diapause in natural populations of $D$. melanogaster.

Diapause has been investigated for many Drosophilids [for example, Drosophila robusta (Carson \& Stalker, 1948; Levitan, 1951), Drosophila littoralis (Lumme et al., 1974; Lumme \& Oikarinen, 1977; Lumme, 1978), Drosophila deflexa Duda (Basden, 1952, 1954a), Drosophila subobscura (Basden, 1954b), Drosophila auraria complex (Kimura, 1984), D. melanogaster (Saunders et al., 1989; Izquierdo, 1991), also see review by Lumme \& Lakovaara, 1983]. However, the genetic resources available for the study of this phenomenon in species other than $D$. melanogaster are limited.

*Correspondence: Dr M. B. Sokolowski, Department of Biology, 4700 Keele Street, Toronto, Ontario, Canada, M3J 1P3.
Until recently, $D$. melanogaster was thought of as a 'day-neutral' species, devoid of an overwintering response, having no diapause (Saunders, 1976). However, Saunders et al. (1989) described the induction of an ovarian diapause in this species. They defined ovarian diapause as a photoperiodically regulated block to vitellogenesis. Ovarian diapause was therefore measured by considering whether flies were in the stage of ovarian development necessary for the onset of vitellogenesis.

Saunders et al. (1989) showed that ovarian diapause is induced in $D$. melanogaster at the critical temperature of $12^{\circ} \mathrm{C}$ and a photoperiod of $10 \mathrm{~h}$ of light and 14 $\mathrm{h}$ of darkness (10L:14D) (Saunders et al., 1989). Newly eclosed $D$. melanogaster females have previtellogenic ovaries; this means that the yolk proteins are not yet deposited in the oocytes (King et al., 1956). Thus, the ovarian immaturity normally present in newly eclosed flies is maintained in diapausing flies.

Vitellogenesis in D. melanogaster is controlled by hormones such as ecdysone and juvenile hormone which influence the expression of three yolk protein genes $Y p 1, Y p 2$ and $Y p 3$ located on the $X$ chromosome (Bownes, 1986). However, it is not known whether ovarian diapause in $D$. melanogaster is affected by the $Y p$ genes. Juvenile hormone is thought to regulate vitellogenesis (Bownes, 1980, 1989), and ovarian diapause (Saunders et al., 1990). Genes regulating diapause and cold hardiness have not yet been localized in any Drosophila species (Denlinger, 1991). 
Here we investigate whether there is a genetic component to variation in ovarian diapause in natural populations of $D$. melanogaster. Specifically, we assess the stages of ovarian development in $D$. melanogaster females from two geographically different sites when placed under the conditions for inducing diapause. We use a 16-reciprocal cross analysis on two isofemale lines with extreme diapause phenotypes to study the heredity of this ecologically relevant trait.

\section{Materials and methods}

Isofemale lines, families of flies each derived from a single inseminated female, were collected from Windsor, Ontario, Canada, and Cartersville, Georgia, U.S.A., in the summer of 1988 by T. Long. We randomly chose six isofemale lines from Windsor and Cartersville (two sites separated from north to south by about $600 \mathrm{~km}$ ) and scored them for diapause as described below.

Prior to the initiation of diapause, flies were maintained at $20^{\circ} \mathrm{C}$, under a $12 \mathrm{~L}: 12 \mathrm{D}$ cycle, with lights on at $0800 \mathrm{~h}$. The sensitive stage for the induction of diapause in $D$. melanogaster is before eclosion and up to 10 hours after eclosion (Saunders et al., 1989). To test for diapause, we collected newly emerged males and virgin females, within $9 \mathrm{~h}$ of eclosion, and placed them into vials at densities of approximately 50 flies with equal sex ratios. Vials contained $5 \mathrm{ml}$ of standard dead yeast-agar-sucrose medium.

The vials of flies were then placed in an incubator at $12^{\circ} \mathrm{C}$ under short day conditions (10L:14D) for 8 to 10 days, after which the females were etherized and dissected in Drosophila saline solution. Ovaries were removed according to Ashburner (1989). Oocytes were found at various stages of development in the ovaries of each fly. The most advanced oocyte present in each fly was used to categorize the fly according to the stages of ovary development described in King (1970).

Flies were scored for the full range of ovary development from stages 1-12. Flies in stages 1-7 were considered to be in diapause because they had previtellogenic ovaries (Saunders et al., 1989). All vials of flies to be dissected were first coded so that the scoring of ovaries could be done at random, without the experimenter's knowledge of the line. Flies from six isofemale lines per site were scored for diapause, and categorized as being in stages $1-7$ or $8-14$ of ovary development. A $G$-test was used to determine whether there was significant variation between sites and between isofemale lines.

The analysis identified two lines $\mathrm{W}$ and $\mathrm{C}$ which differed significantly in their diapause response. These lines were dissected as described previously after exposure to short daylengths (10L:14D) and long daylengths $(18 \mathrm{~L}: 6 \mathrm{D})$ at $12^{\circ} \mathrm{C}$. A 16 -reciprocal cross analysis was performed between these lines to analyse the hereditary components important to the diapause phenomenon in D. melanogaster. The crossing scheme and heritable components associated with each cross are shown in Table 1.

Differences between crosses that share three of four factors in common were compared to determine the effect of the fourth factor. For example, female progeny of cross 5 and 6 have the same autosomai contribution, $3 / 4$ of their autosomes from $\mathrm{W}$ and $1 / 4$ from $C$, which we term $B_{w}$. They also share permanent cytoplasmic factors (from W) and transient maternal factors (from W) but differ in the origin of their $X$ chromosomes. Cross 5 females have $X$-chromosomes from W parents and cross 6 females have one $X$ chromosome from the $\mathrm{W}$ and one from the $\mathrm{C}$ parent (we have called this an $\mathrm{F}_{1}$ complement of $X$ chromosomes). Refer to crosses outlined in Table 1 for cross numbers.

A number of a priori comparisons were made (Table 2) and the data were analysed with a $G$-test using BIOM (Rohlf, 1984).

\section{Results}

As expected, Windsor, the more northern site, showed a higher percentage of flies in diapause than Cartersville $[29$ per cent for Windsor as compared with 55 per cent for Cartersville $(P<0.0025)]$. The nested analysis of the data from the six isofemale lines examined for each location, showed a significant line effect $\left(G_{10}=55.59 ; P<0.001\right)$ and a significant site effect $\left(G_{1}=28.89 ; P<0.001\right)$. The variation observed in the isofemale lines within each site enabled us to identify the $\mathrm{W}$ and $\mathrm{C}$ lines which differed significantly in diapause. The $\mathrm{W}$ and $\mathrm{C}$ lines were used in our genetic analysis. After 8 days at $12^{\circ} \mathrm{C}$ significantly more $\mathrm{W}$ and $\mathrm{C}$ females were in diapause at short daylengths than at long daylengths. For W, 90 per cent of females were in diapause at $10 \mathrm{~L}: 14 \mathrm{D}$ compared with 50 per cent at $18 \mathrm{~L}: 6 \mathrm{D} \quad\left(G_{1}=10.25, P<0.005\right)$ whereas for $C, 32$ per cent of females were in diapause at $10 \mathrm{~L}: 14 \mathrm{D}$ compared with 14 per cent at $18 \mathrm{~L}: 6 \mathrm{D}$ $\left(G_{1}=3.95, P<0.05\right)$.

The percentage of flies in diapause for each cross is shown in Table 1. The 16-reciprocal crosses shown in this table allow for the separation of hereditary components into autosomal effects, $X$-chromosome effects, transient maternal and permanent cytoplasmic factors (see Wahlsten, 1979; de Belle \& Sokolowski, 1987; Bauer \& Sokolowski, 1988). The latter two can be thought of as non-chromosomally inherited 
Table 1 Sixteen crosses between Cartersville (C) and Windsor (W) D. melanogaster strains used to separate their hereditary components and the percentages of females in diapause for each cross

Hereditary components

\begin{tabular}{|c|c|c|c|c|c|c|c|c|c|}
\hline Cross no. & Mother & & Father & Autosomes & $\begin{array}{l}\text { Permanent } \\
\text { cytoplasmic } \\
\text { factors }\end{array}$ & $\begin{array}{l}\text { Transient } \\
\text { maternal } \\
\text { factors }\end{array}$ & $\begin{array}{l}\text { Sex-chromosomes } \\
\text { female } \\
\text { XX }\end{array}$ & $\begin{array}{l}\text { Sample } \\
\text { size } \\
(n)\end{array}$ & $\begin{array}{l}\% \\
\text { diapause }\end{array}$ \\
\hline \multicolumn{10}{|c|}{ Parental strains } \\
\hline 1 & W & $x$ & W & W & W & W & W & 52 & 63.46 \\
\hline 2 & $\mathrm{C}$ & $\times$ & $\mathrm{C}$ & $\mathrm{C}$ & $\mathrm{C}$ & $\mathrm{C}$ & $\mathrm{C}$ & 74 & 17.57 \\
\hline \multicolumn{10}{|c|}{ Reciprocal $F_{1}$ hybrids } \\
\hline 3 & W & $x$ & $\mathrm{C}$ & $F_{1}$ & W & W & $F_{1}$ & 31 & 6.45 \\
\hline 4 & $\mathrm{C}$ & $x$ & W & $F_{1}$ & $\mathrm{C}$ & $\mathrm{C}$ & $F_{1}$ & 29 & 6.90 \\
\hline \multicolumn{10}{|c|}{ Reciprocal backcrosses } \\
\hline 5 & W & $x$ & $(\mathrm{~W} \times \mathrm{C})$ & $B_{w}$ & W & W & W & 20 & 35.00 \\
\hline 6 & W & $x$ & $(\mathrm{C} \times \mathrm{W})$ & $B_{w}$ & W & W & $F_{1}$ & 18 & 38.89 \\
\hline 7 & $\mathrm{C}$ & $x$ & $(\mathrm{~W} \times \mathrm{C})$ & $\mathrm{B}_{\mathrm{c}}^{w}$ & $\mathrm{C}$ & $\mathrm{C}$ & $F_{1}$ & 49 & 0.00 \\
\hline 8 & $\mathrm{C}$ & $x$ & $(\mathrm{C} \times \mathrm{W})$ & $\mathrm{B}_{\mathrm{c}}$ & $\mathrm{C}$ & $\mathrm{C}$ & $\mathrm{C}$ & 21 & 4.76 \\
\hline 9 & $(\mathrm{~W} \times \mathrm{C})$ & $x$ & W & $B_{w}^{c}$ & W & $F_{1}$ & $\mathrm{~B}_{\mathrm{w}}$ & 13 & 30.77 \\
\hline 10 & $(\mathrm{C} \times \mathrm{W})$ & $x$ & W & $B_{w}^{w}$ & $\mathrm{C}$ & $F_{1}$ & $B_{w}$ & 18 & 16.67 \\
\hline 11 & $(\mathrm{~W} \times \mathrm{C})$ & $x$ & $\mathrm{C}$ & $B_{c}$ & W & $F_{1}$ & $\mathrm{~B}_{\mathrm{c}}$ & 19 & 5.26 \\
\hline 12 & $(\mathrm{C} \times \mathrm{W})$ & $x$ & $\mathrm{C}$ & $\mathrm{B}_{\mathrm{c}}$ & $\mathrm{C}$ & $F_{1}$ & $\mathrm{~B}_{\mathrm{c}}$ & 30 & 0.00 \\
\hline \multicolumn{10}{|c|}{ Reciprocal $F_{2}$ hybrids } \\
\hline 13 & $(\mathrm{~W} \times \mathrm{C})$ & $x$ & $(\mathrm{~W} \times \mathrm{C})$ & $F_{2}$ & W & $F_{1}$ & $B_{w}$ & 39 & 28.21 \\
\hline 14 & $(\mathrm{~W} \times \mathrm{C})$ & $x$ & $(\mathrm{C} \times \mathrm{W})$ & $\mathrm{F}_{2}$ & W & $F_{1}$ & $\mathrm{~B}_{\mathrm{c}}$ & 31 & 29.03 \\
\hline 15 & $(\mathrm{C} \times \mathrm{W})$ & $x$ & $(\mathrm{~W} \times \mathrm{C})$ & $\mathrm{F}_{2}$ & $\mathrm{C}$ & $F_{1}$ & $B_{w}$ & 42 & 2.38 \\
\hline 16 & $(\mathrm{C} \times \mathrm{W})$ & $x$ & $(\mathrm{C} \times \mathrm{W})$ & $\mathrm{F}_{2}$ & $\mathrm{C}$ & $F_{1}$ & $\mathrm{~B}_{\mathrm{c}}$ & 58 & 39.65 \\
\hline
\end{tabular}

Components characteristic of: $F_{1}-F_{1 \text { hybrid }} B_{w}-$ backcross to Windsor parental strain; $B_{c}-$ backcross to Cartersville parental strain; $F_{2}-F_{2}$ hybrid.

Table modified from Wahlsten (1979) and Sokolowski (1992).

Table 2 Reciprocal cross analysis of the Cartersville $(C)$ and Windsor $(W)$ isofemale lines of Drosophila melanogaster

\begin{tabular}{|c|c|c|c|}
\hline Source & Crosses compared & d.f. & $G$-statistic \\
\hline Parental strains, W \& C & 1 vs. 2 & 1 & $28.33^{\text {**** }}$ \\
\hline Dominance & $(3,4)$ vs. 1 & 1 & $43.76^{* * *}$ \\
\hline Reciprocal $F_{1} \mathrm{~s}$ & 3 vs. 4 & 1 & 0.01 \\
\hline \multicolumn{4}{|l|}{ X-chromosome: } \\
\hline (in W background) & 5 vs. 6 & 1 & 0.06 \\
\hline (in C background) & 7 vs. 8 & 1 & 0.18 \\
\hline \multicolumn{4}{|l|}{ Cytoplasmic factors } \\
\hline (in W background) & 9 vs. 10 & 1 & 0.79 \\
\hline (in C background) & 11 vs. 12 & 1 & 0.05 \\
\hline \multicolumn{4}{|l|}{ Maternal effects } \\
\hline (in W background) & $(5,6)$ vs. $(9,10)$ & 1 & 1.67 \\
\hline (in C background) & $(7,8)$ vs. $(11,12)$ & 1 & 0.05 \\
\hline Backcrosses to $\mathrm{W}\left(\mathbf{B}_{\mathrm{w}}\right)$ & 5 vs. 6 vs. 9 vs. 10 & 3 & 2.46 \\
\hline Backcrosses to $\mathrm{C}\left(\mathrm{B}_{\mathrm{c}}\right)$ & 7 vs. 8 vs. 11 vs. 12 & 3 & 2.99 \\
\hline Reciprocal $\mathrm{F}_{2} \mathrm{~S}$ & 13 vs. 14 vs. 15 vs. 16 & 3 & $22.82^{* * *}$ \\
\hline
\end{tabular}

$\mathrm{W}$ background $=$ all autosomes from $\mathrm{W}$ parent $\mathrm{C}$ background $=$ all autosomes from $C$ parent. $(3,4)$ indicates cross 3 pooled with 4 .

*** $P<0.001$. 
components. Transient maternal factors such as the action of the mother's genes on the zygote, affect only the $F_{1}$ progeny whereas permanent cytoplasmic factors such as effects of mitochondrial genes can be passed on through the maternal parent from generation to generation (Wahlsten, 1979; Bauer \& Sokolowski, 1988). $Y$-chromosome effects could not be tested because the diapause response is a sex specific (female) response.

The results of our genetic analysis are shown in Table 2. We found a significant difference between the parental lines (Table 2). The reciprocal $F_{1}$ crosses did not differ significantly from each other. When the data from the $F_{1}$ crosses were pooled they differed significantly from the $\mathrm{W}$ parent. Therefore, the $\mathrm{C}$ response (less flies in diapause) is dominant to the $\mathrm{W}$ one. The pooled $F_{1}$ crosses did not differ significantly from the $\mathrm{C}$ parent indicating no overdominance $\left(G_{1}=3.65\right.$, ns $)$. All other comparisons were not significant indicating that the $X$-chromosome, maternal and permanent cytoplasmic factors did not contribute to differences between the lines.

The analyses (Table 2), show that it is reasonable to pool most of the reciprocal cross data. The percentage of flies in diapause for the parental, and pooled $F_{1}, B_{c}$, $B_{w}$ and $F_{2}$ crosses are shown in Fig. 1. Overall, our results fit a simple autosomal model of inheritance with the lower percentage in diapause dominant to the higher one. The $F_{1}$ crosses and the $B_{c}$ do not differ from the $C$ parent, and the $B_{w}$ and $F_{2}$ crosses are intermediate between the two parents. For this analysis we have pooled all four $F_{2}$ crosses; however, cross 15 did differ significantly from the others. It had a significantly lower percentage of flies in diapause than the other $F_{2}$ crosses. This result did not reflect consistent differences in hereditary components and was probably caused by using isofemale parental lines rather than

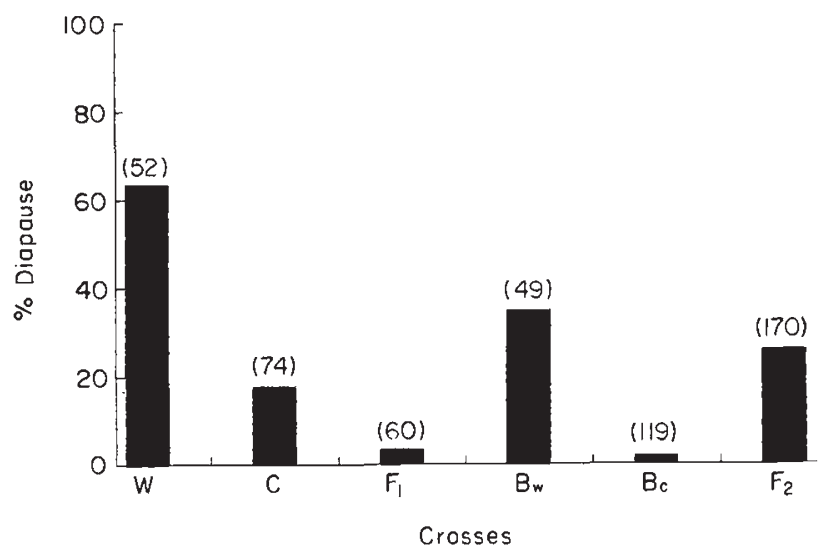

Fig. 1 Graph showing the percentage of Drosophila melanogaster in diapause for the parental lines $F_{1} s$, backcrosses $B_{w}$ and $B_{c}$, and $F_{2} s$. Sample sizes are shown in brackets. isogenic ones. [The pooled proportion of flies in diapause for all $\mathrm{F}_{2}$ crosses did not differ significantly from the pooled proportion in diapause when cross 15 was not included $\left(G_{1}=2.09, \mathrm{~ns}\right)$.]

We examined whether the backcross and $F_{2}$ data fitted the expected Mendelian ratios for a simple autosomal model with complete dominance. No significant differences were found between observed and expected 1:1 ratios, in the backcrosses to the recessive W parent $\left(\chi_{1}^{2}=2.6\right.$, ns $)$ or between the $3: 1$ ratios expected in the $F_{2}$ crosses $\left(\chi_{1}^{2}=0.1\right)$. Thus we cannot reject the hypothesis of a simple autosomal model for this trait in these populations.

\section{Discussion}

Isofemale lines from Windsor have significantly higher percentages of flies in diapause than those from Cartersville when tested under the conditions described in this paper. Significant variation in diapause was also present between isofemale lines within each site. Variation within sites for this trait could enable flies to survive in temporally and spatially changing microhabitats.

The ability to go into diapause may increase survival in northern populations of D. melanogaster and, therefore, may have been selected in these environments. Saunders et al. (1989) hypothesized that populations in the southern latitudes should not show a true diapause in contrast to populations further north which should show a photoperiodic diapause. Our study supports this hypothesis since the more southern population (Cartersville) had significantly less flies entering diapause than the northern population from Windsor. Females from both $\mathrm{W}$ and $\mathrm{C}$ lines were able to exhibit a photoperiodically regulated diapause with a significantly higher percentage of flies in diapause at short days $(10 \mathrm{~L}: 14 \mathrm{D})$ as compared to long days (18L:6D). Interestingly, W flies differentiated between short and long days better than $\mathrm{C}$ flies. However, a clinal study of this ovarian diapause is needed to determine whether natural selection has acted to shape the diapause response in $D$. melanogaster.

Northern species of Drosophila are often univoltine, surviving the winter in a photoperiodic diapause (Lumme, 1978). Lumme et al. (1975) and Lumme \& Oikarinen (1977) found that the photoperiodic diapause of $D$. littoralis was attributable to a single autosomal locus. The character that they measured was the ability of the flies to distinguish between long and short days. They concluded that the longer critical daylength, a 'northern' character, was incompletely dominant to the shorter one (Lumme, 1978). In a later paper, Lumme (1981) described a gene for this critical 
day length character, which they localized to the fourth chromosome of $D$. littoralis.

Researchers examining the genetics of diapause in other insects have found a polygenic basis of inheritance (see reviews in Beck, 1980 and Danks, 1987). The genetics of egg diapause in the silk moth, Bombyx mori, was shown to be based on three sex-linked genes and three autosomal genes (Lees, 1955). Lakovaara et al. $(1972,1973)$ showed that adult reproductive diapause was under polygenic control in $D$. ovivororum and in $D$. littoralis (but see comment in Lumme \& Oikarinen, 1977 and Hoy, 1978). It is not surprising that components of diapause have a different genetic basis in various insects since diapause may have arisen independently many times during natural selection (Hoy, 1978). Thorough genetic dissection of the diapause phenomenon is only possible in $D$. melanogaster.

We measured one aspect of the photoperiodic response in $D$. melanogaster, namely the ability to enter diapause at $12^{\circ} \mathrm{C}$ and $10 \mathrm{~L}: 14 \mathrm{D}$. In our study the 'northern' character (the Windsor response) was completely recessive to the 'southern' (Cartersville) one. The results of the reciprocal cross analysis did not allow us to reject the hypothesis that our measure of diapause in $D$. melanogaster is under the control of a single autosomal gene.

This genetic analysis, however, was accomplished using parents from isofemale lines which are not completely homozygous for all loci. To further address this issue, isogenic lines for the autosomes should be constructed to assess Mendelian ratios and estimate gene number from the $\mathrm{F}_{2}$ crosses. This would also allow for reassessment of the differences we found in one of the $\mathrm{F}_{2}$ crosses. A simple genetic basis for naturally occurring variation in ovarian diapause in $D$. melanogaster should enable the localization of the gene responsible for this trait. This has been done for the foraging locus of D. melanogaster, which is responsible for the naturally occurring rover/sitter behavioural polymorphism (de Belle et al., 1989).

The genetic dissection of the ovarian diapause phenomenon in $D$. melanogaster can also be accomplished through various kinds of mutagenesis; for example, EMS, gamma radiation and transposable elements followed by screening for diapause mutants (Grigliatti, 1986). Characterization of the inheritance of diapause will contribute to our understanding of when genes are activated in response to photoperiodic time measurement, and therefore the induction, maintenance and termination of the phenomenon. Genetic and molecular characterization of genes important to diapause in D. melanogaster should also shed light on the genetic control of time measurement in insects.

\section{Acknowledgements}

We thank John Ringo for discussions leading to the start of this project and gratefully acknowledge all the people in our laboratory who were preyed upon to cryptically code vials before dissection of flies. This work was supported by a Human Frontier Science Grant and a Natural Sciences and Engineering Research Council Grant to M.B.S.

\section{References}

ASHBURNer, M. 1989. Drosophila: A Laboratory Handbook. Cold Spring Harbor Laboratory Press, NY.

BASDEN, E. B. 1952. Some Drosophilidae (Diptera) of the British Isles. Ent. Mon. Mag., 88, 200-201.

BASDEN, E. B. 1954a. The distribution and biology of Drosophilidae (Diptera) in Scotland, including a new species of Drosophila. Trans. Roy. Soc. Edinb., 62, 602-654.

BASDEN, E. B. 1954b. Diapause in Drosophila (Diptera: Drosophilidae). Proc. R. Ent. Soc. Lond., (A) 29, 114-118.

BAUER, S. J. AND SOKOLOWSK1, M. B. 1988. Autosomal and maternal effects on pupation in Drosophila melanogaster. Behav. Genet., 18, 81-97.

BECK, S. D. 1980. Insect Photoperiodism, 2nd ed. Academic Press, New York.

BOWNES, M. 1980. The use of yolk protein variations in Drosophila species to analyze the control of vitellogenesis. Differentiation, 16, 109-116.

BOWNES, M. 1986. Expression of genes coding for vitellogenin (yolk proteins). A. Rev. Ent., 31, 507-531.

BOWNES, M. 1989. The roles of juvenile hormone, ecdysone and the ovary in the control of Drosophila vitellogenesis. J. Insect Physiol., 35, 409-413.

CARSON, H. L. AND STALKER, H. D. 1948. Reproductive diapause in Drosophila robusta. Proc. Natl. Acad. Sci. U.S.A., 34, 124-129.

DANKS, H. v. 1987. Insect Dormancy: An Ecological Perspective. Biological Survey of Canada (Terrestrial Arthropods), Ottawa, p. 439.

DE BELLE, J. S. AND SOKOLOWSKI, M. B. 1987. Heredity of rover/ sitter: Alternative foraging strategies of Drosophila melanogaster. Heredity, 59, 73-83.

DE BELLE, J. S., HILLIKER, A. J. AND SOKOLOWSK1, M. B. 1989. Genetic localization of foraging (for): a major gene for larval behavior in Drosophila melanogaster. Genetics, 123, 157-163.

DENLINGER, D. L. 1991. Relationship between cold hardiness and diapause. In: Lee, R. E. Jr. and Denlinger D. L. (eds) Insects At Low Temperature, Chapman and Hall, London, pp. 174-198.

DINGLE, H. (ED.) 1978. Evolution of Insect Migration and Diapause. Springer-Verlag, New York.

GRIGLiatTI, T. 1986. Mutagenesis. In: Roberts, D. B. (ed.) Drosophila: A Practical Approach, IRL Press, Oxford, pp. 31-58. 
HOY, M. А. 1978. Variability in diapause attributes of insects and mites: some evolutionary and practical implications. In: Dingle, H. (ed.) Evolution of Insect Migration and Diapause, Springer-Verlag, New York, pp. 101-126.

IZQUIERDo, J. I. 1991. How does Drosophila melanogaster overwinter? Entomol. Exp. Appl., 59, 51-58.

KIMURA, M. T. 1984. Geographic variation of reproductive diapause in the Drosophila auraria complex (Diptera:Drosophilidae). Physiol. Entomol., 9, 425-431.

KING, R. C. 1970. Ovarian Development in Drosophila melanogaster. Academic Press, New York.

KING, R. C., RUBINSON, A. C. AND SMITH, R. F. 1956. Oogenesis in adult Drosophila melanogaster. Growth, 20, 121-157.

LAKovaARA, S., SAURA, A., KoREF-SANTIBAÑEZ, S. AND EHRMAN, L. 1972. Aspects of diapause and its genetics in northern drosophilids. Hereditas, 74, 89-96.

LAKOVAARA, S., LUMME, J. AND OIKARINEN, A. 1973. Genetics and evolution of diapause in European species of the Drosophila virilis group. Genetics, 74, s143.

LeEs, A. D. 1955. The Physiology of Diapause in Arthropods. Cambridge University Press, London.

LEVITAN, M. 1951. Experiments on chromosomal variability in Drosophila robusta. Genetics, 36, 285-305.

LUMME, J. 1978. Phenology and photoperiodic diapause in northern populations of Drosophila. In: Dingle, H. (ed.) Evolution of Insect Migration and Diapause, SpringerVerlag, New York, pp. 145-170.

LUMME, J. 1981. Localization of the genetic unit controlling the photoperiodic adult diapause in Drosophila littoralis. Hereditas, 94, 241-244.

LUMME, J. AND LAKOVAARA, s. 1983. Seasonality and diapause in Drosophilids. In: Ashburner, M., Carson, H. L. and Thompson, J. N. Jr. (eds) Genetics and Biology of Drosophila, Vol. 3d, Academic Press, London, pp. 171-220.
LUMME, J. AND OIKARINEN, A. 1977. The genetic basis of the geographically variable photoperiodic diapause in Drosophila littoralis. Hereditas, 86, 129-142.

LUMME, J., OIKARINEN, A., LAKovaARA, S. AND ALATAlo, R. 1974. The environmental regulation of adult diapause in Drosophila littoralis. J. Insect Physiol., 20, 2023-2033.

LUMME, J., LAKOVAARA, S., OIKARINEN, A. AND LOKKI, J. 1975. Genetics of the photoperiodic diapause in Drosophila littoralis. Hereditas, 79, 143-148.

OIKARINEN, A. AND LUMME, J. 1979. Selection against photoperiodic reproductive diapause in Drosophila littoralis. Hereditas, 90, 119-125.

ROHLF, F. J. 1984. BIOM: a Statistical Package to Accompany the Text Biometry. State University of New York, Stony Brook, New York.

SAUnders, D. s. 1976. Insect Clocks. Pergamon Press, Oxford.

SAUNDERS, D. S., HEINRICH, v. C. AND GILBERT, L. I. 1989. Induction of diapause in Drosophila melanogaster: Photoperiodic regulation and the impact of arrhythmic clock mutations on time measurement. Proc. Natl. Acad. Sci. U.S.A., 86, 3748-3752.

SAUNDERS, D. S., RICHARD, D. S., APPLEBAUM, S. W., MA, M. AND GILBERT, L. I. 1990. Photoperiodic diapause in Drosophila melanogaster involves a block to juvenile hormone regulation of ovarian maturation. Gen. Comp. Endocrinol., 79, $174-184$.

sokolowski, M. в. 1992. Genetic analysis of behavior in the fruit fly, Drosophila melanogaster. In: Goldowitz, D., Wahlsten, D. and Wimer, R. E. (eds) Techniques for the Genetic Analysis of Brain and Behavior, Elsevier Science Publishers, Amsterdam, pp. 497-512.

WAHLSTEN, D. 1979. A critique of the concepts of heritability and heredity in behavioral genetics. In: Royce, J. R. and Mos, L. (eds) Theoretical Advances In Behavioral Genetics, Sijthoff and Nordhoff, Germantown, MD, pp. 426-481. 